\title{
Synthesis and Characterization of Zinc Oxide Doped Mesoporous Silica SBA-16 and Anti-bacterial Property
}

\author{
Nidhi', Sunita Dahiya ${ }^{1}$, Atul Kumar ${ }^{2}$ and Surender Duhan ${ }^{2}$ \\ ${ }^{1}$ Department of Physics, Baba Mastnath University, Asthal Bohar, Rohtak, Haryana, India \\ ${ }^{2}$ Department of Physics, Deenbandhu Chhotu Ram University \\ of Science and Technology, Murthal, Sonipat, Haryana, India \\ Corresponding author email: surender6561@gmail.com
}

\section{ABSTRACT}

In this research, article SBA-16 was synthesized by using hydrothermal process and ZnO nanoparticles by using sol-gel method. ZnO nanoparticles were introduced further into the mesopores of SBA-16 through post impregnation method. The doping of ZnO nanoparticles into SBA-16 was confirmed by their Fourier Transformed Infrared Spectroscopy (FTIR) analysis, X-ray diffraction (XRD), and small-angle X-ray Scattering graph (SAXS). The morphological analysis of the prepared sample was done by Scanning Electron Microscopy (SEM), and their lattice cell parameter with symmetry was be analyzed by performing Transmission Electron Microscope (TEM). The anti-bacterial property of SBA-16-ZnO nanocomposite was examined against $E$. coli and $S$. aureus bacteria.

KEY WORDS: ZNO, SBA-16, SBA-16-ZNO NANOCOMPOSITE, ANTI-BACTERIAL PROPERTY, ETC.

\section{INTRODUCTION}

SBA-16 is a modern mesoporous, large cage, Im3m silicium substance with large pores and high hydrothermal stability. The SBA-16 also exhibits high thermal and mechanical stability and is environment friendly, making it a suitable material for a wide range of applications. It can be applied as a support material of catalysts and planning for the production of orderly mesoporous carbon in environmental treatment for adsorption and separation. Its practical uses, including catalysts, absorbents, and sensors, have been extensively published. However, the study has not been published thoroughly on many morphologies of mesoporous SBA-16 materials. The synthesis of mesoporous materials with other materials changes in synthetic sources, stirrings, and reaction temperatures may achieve morphologies.

Biosc Biotech Res Comm P-ISSN: 0974-6455 E-ISSN: 2321-4007

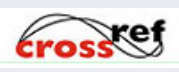

Identifiers and Pagination

Year: 2021 Vol: 14 No (9) Special Issue

Pages: 194-197

This is an open access article under Creative

Commons License Attribn 4.0 Intl (CC-BY). DOI: $h t t p: / / d x . d o i . o r g / 10.21786 / b b r c / 14.9 .37$
The Zinc Oxide Nanoparticle $(\mathrm{ZnO})$ is a wideband semiconductor that attracts considerable attention to fundamental studies and possible applications in different research areas. $\mathrm{ZnO}$ is a versatile, functional material, with its superior qualities being applied potentially in catalysts, transducers, semiconductors, microelectronics, textiles, cosmetics, water treatment, and others. In addition to antibiotics and bactericides, $\mathrm{ZnO}$ displays antimicrobial activity and anti-inflammatory characteristics that provide more efficient, less expensive, and less toxic alternatives. In recent years, several groups have produced the preparation of nano-size $\mathrm{ZnO}$ particles through sol-gel methods (Kumar et al., 2020).

Antibacterial activity against Gram-Positive gramnegative bacteria is shown by nanoparticles of zinc oxide. Nanoparticles with zinc oxide are thought to be non-toxic, bio-safe, and biocompatible. SBA-16ZnO nanocomposite's antibacterial activity has not previously been investigated against E.coli and S. aureus. Although specific assertions were suggested, such as hydrogen peroxide development, the critical factor of the antibacterial activity or the attachment of $\mathrm{ZnO}$ particles on the Bacterial Surface could be a mechanism. The mechanisms of ZnO's antibacterial activity are not fully known. This work, therefore, tries to manufacture
Article Information

Received: 06 ${ }^{\text {th }}$ May 2021

ccepted after revision: $18^{\text {th }}$ July 2021 
nanocomposites SBA-16-ZnO and verify their vigorous antibacterial activity for bacteria of E.coli and $S$. aureus (Sirelkhatim et al., 2015).

In this research, article SBA-16 was synthesized by using hydrothermal process and $\mathrm{ZnO}$ nanoparticles by using sol-gel method. ZnO nanoparticles were introduced further into the mesopores of SBA-16 through post impregnation method. The doping of $\mathrm{ZnO}$ nanoparticles into SBA-16 was confirmed by their Fourier Transformed Infrared Spectroscopy (FTIR) analysis X-ray diffraction (XRD) and small-angle X-ray Scattering graph (SAXS). The morphological analysis of the prepared sample was done by Scanning Electron Microscopy (SEM), and their lattice cell parameter with symmetry was be analyzed by performing Transmission Electron Microscope (TEM). The research work shows successful preparation of $\mathrm{ZnO}$ doped SBA-16, which can be significantly applicable in several industrial applications such as catalyst, antibiofilm industries, targeted drug delivery, etc. The results will assist in discovering an appropriate alternative for controlling E.coli and S. aureus infection.

\section{Experimentation}

2.1. Synthesis of SBA-16: SBA-16 was synthesized to retain the $\mathrm{pH}$ of solution $5.94 \mathrm{gm}$ 2M HCL in the solution by dissolving 3gm Pluronic P127 in $144 \mathrm{gm}$ distilled water. $9 \mathrm{gm}$ n-butanol was applied carefully into the solution and stirred the solution for the next 3 hours to prepare a clear solution. After $3 \mathrm{hrs}$ of stirring, 14.2gm TEOS dropwise applied to the earlier stirring solution and stirred at a temperature of $38^{\circ} \mathrm{C}$ for another 24 hours. The processed hydrothermal solutions were applied to an autoclave with Teflon and placed in the microwave autoclave at $100^{\circ} \mathrm{C}$ for 24 hours. The final stage was washed three times with water purified and calcinated for 5 hours at $550^{\circ} \mathrm{C}$ (Praseptiangga et al., 2020).

2.2. Synthesis of SBA-16/ZnO Nanocomposite: SBA-16/ $\mathrm{ZnO2}$ nanocomposite has been prepared by impregnation of zinc acetate solution into SBA-16. The synthesis process was performed by adding $0.901 \mathrm{~g}$ zinc acetate into $42 \mathrm{ml}$ ethanol and stirred for 2 hours at $70^{\circ} \mathrm{C}$. The solution was cooled to room temperature, which resulted in a heavy stirring of $0.5 \mathrm{~g}$ of SBA-16. In order to extract the contaminant, the resulting blend has been dried for 24 hours at $80^{\circ} \mathrm{C}$. Samples were consequently calcinated in the air by rising ambient temperature over 1 hour and keeping $550{ }^{\circ} \mathrm{C}$ for 1 hour from room temperature to 550 ${ }^{\circ} \mathrm{C}$ (González-Rodríguez et al., 2020).

2.3. Anti-bacterial Evaluation: The antibacterial effect of SBA-16-ZnO nanocomposite against E.coli and S. aureus bacteria was evaluate using the previously mentioned procedure. Discs of SBA-16-ZnO nanocomposite and SBA-16 were prepared, and distilled water disks were employed as control. The culture was kept for overnight incubation at $37^{\circ} \mathrm{C}$. The measurement of inhibition-zone diameter was used to assess antibacterial activity.

\section{Characterization:}

3.1. Ftir: At a prominent peak at $3500 \mathrm{~cm}-1$, FTIR pattern, the $0-\mathrm{H}$-bond of the silanol groups and the water molecules were reflected in the samples. The $\mathrm{C}-\mathrm{H}$ vibration should be present at a low peak at $2890 \mathrm{~cm}-1$ and suggest that virtually all of the tensile material has been extracted. A wavenumber $1635, \mathrm{~cm}-1$ is the bending vibration of the $\mathrm{C}-\mathrm{H}$. Siloxane (-Si-O-Si-) is distinguished by its elevated height at $1082 \mathrm{~cm}-1$. The vibration of the silanol groups' Si-OH bond extending is observed at 961 $\mathrm{cm}-1$, and the $490 \mathrm{~cm}-1 \mathrm{Si}-0$ bond rocking vibration was observed. These functional classes fit TEOS's SBA16 FTIR pattern. The drop in $\mathrm{Si}-\mathrm{OH}$ group strength in the graph SBA-16-ZnO nanocomposite implies that ZnO alters the inner surface. SBA-16-ZnO nanocomposite spectrum FTIR exhibits wavelength propagation peaks at $961.64 \mathrm{~cm}-1$ and $474 \mathrm{~cm}-1$, respectively, for Si-0-Zn and $\mathrm{ZnO}$. The peak position of $\mathrm{ZnO}$ has been marginally modified due to the rise in $\mathrm{ZnO}$ mass as the frequency of vibration is inversely proportional to the mass of the vibrating molecule (Cao et al., 2019).

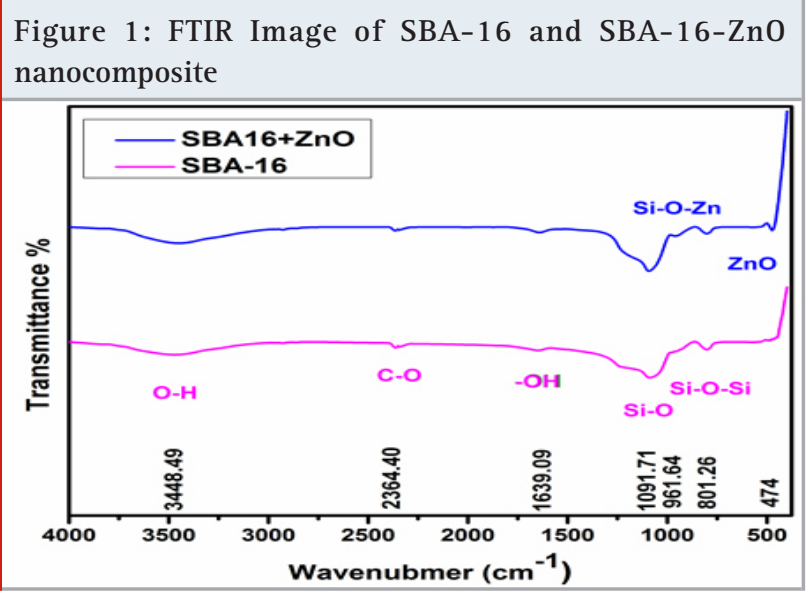

3.2. Xrd: X-ray diffraction of SBA-16 and SBA-16-ZnO nanocomposite is demonstrated in figure 2 . The spectrum of SBA-16-ZnO nanocomposite comprises peaks with the following indexable ranges: $(2)=32.5^{\circ},\left(35.12^{\circ}, 36.93^{\circ}\right.$, (111), (200), (210) and (220). PDF \# 13-0311 of the JCPDS database coordinates the observed diffractions patterns effectively. A broad hump at a $24^{\circ}$ angle suggesting the amorphous structure of SBA- 16 .

Figure 2: XRD graph of SBA-16 and SBA-16-ZnO nanocomposite

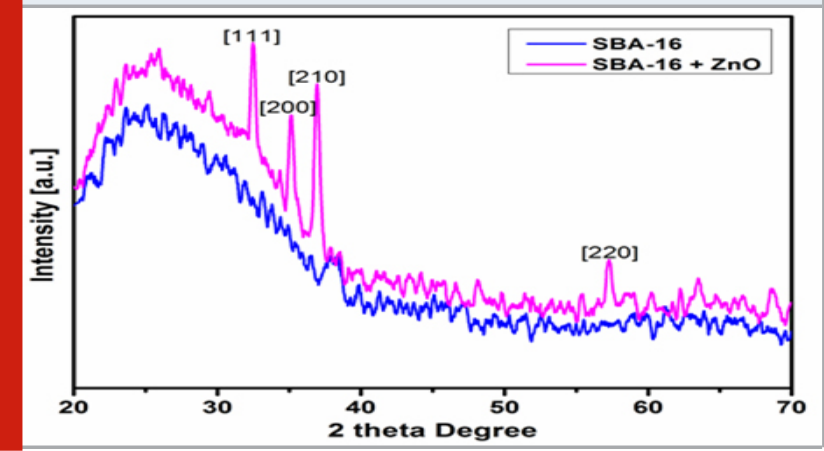


3.3. Saxs: Their long-range order is detected by smallangle X-ray dispersion (SAXS $0.5^{\circ}-5^{\circ}$ ). Non-crystalline materials are not at a higher angle. Pure SBA-16 and SBA-16-Zn0 nanocomposite are represented in Figure3. The pure SAXS pattern of the SBA-16 includes two $0.96^{\circ}$ and $1.30^{\circ}$ reflections, representing respectively (110) and (211) planes. The formation of the SBA-16 cubic structure Im3M is verified. SBA-16 ZnO nanocomposite also represented SAXS data with a single peak at a frequency of $0.99^{\circ}$ but with (111) relatively low amplitude. The second highest peak in this pattern resolved due to the introduction of nanoparticles of $\mathrm{ZnO}$ into the pores of SBA-16 (Bruckner et al., 2021).

Figure 3: SAXS of SBA-16 and SBA-16-ZnO nanocomposite

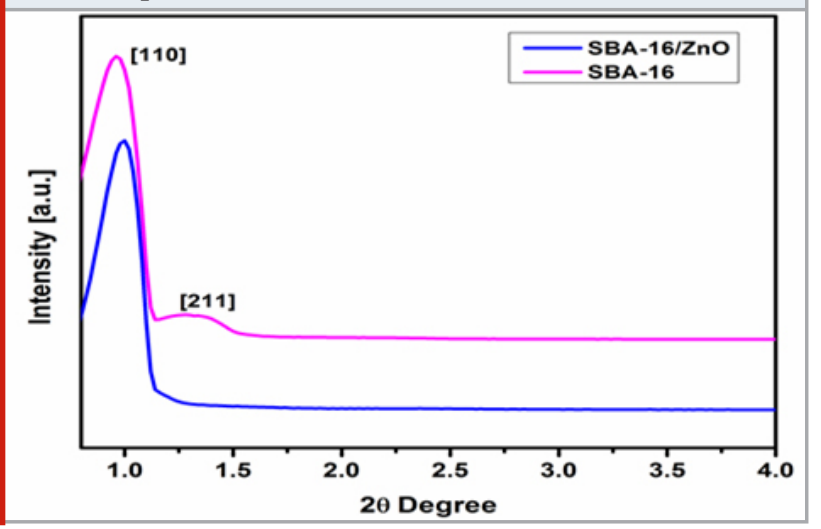

Figure 4: SEM Image of SBA-16 and SBA-16-ZnO nanocomposite.

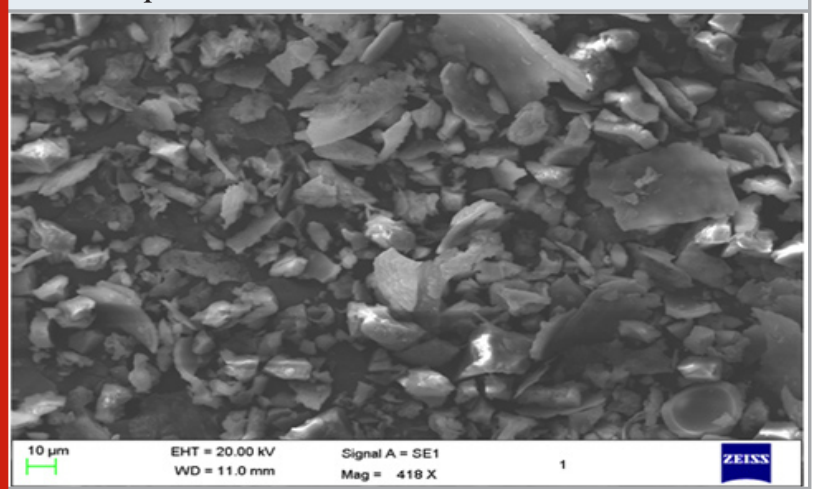

3.4. Sem: Figure 3 shows the $\mathrm{ZnO}$ doped SBA-16 nanocomposite SEM image. The appearance of sphericalshaped particles is seen in SEM images of SBA-16-ZnO nanocomposite. For the sample, the smaller particle size is about $100 \mathrm{~nm}$. It should be noticed that as a result of particle agglomerations, the particles can merge and that poly-crystallinity is increasing. The picture above indicates that there are also smaller crystals around the particles in addition to spherical spheres.

3.5. Tem: The TEM experiments have been used to research the mesoporous properties of the SBA-16-ZnO nanocomposite. The TEM micrographs of the SBA-16$\mathrm{ZnO}$ nanocomposite appear in figure 4 . The SBA-16-ZnO nanocomposite has a three-dimensional mesoporous hexagonal form that is similar to SBA-16. The unit cell parameter is roughly $11.6 \mathrm{~nm}$, and this correlates well to $12.5 \mathrm{~nm}$. Through TEM analysis, the $\mathrm{ZnO}$ clusters can be significantly seen on canals. This may be because, like the $\mathrm{ZnO}$ clusters encapsulated within the mesopores, the picture contrast between the silica frame and the $\mathrm{ZnO}$ cluster is high.

Figure 5: SEM Image of SBA-16 and SBA-16-ZnO nanocomposite

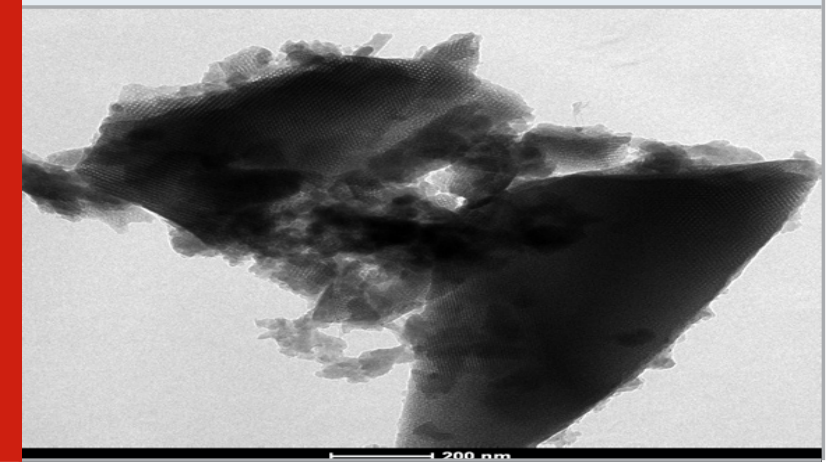

Figure 6

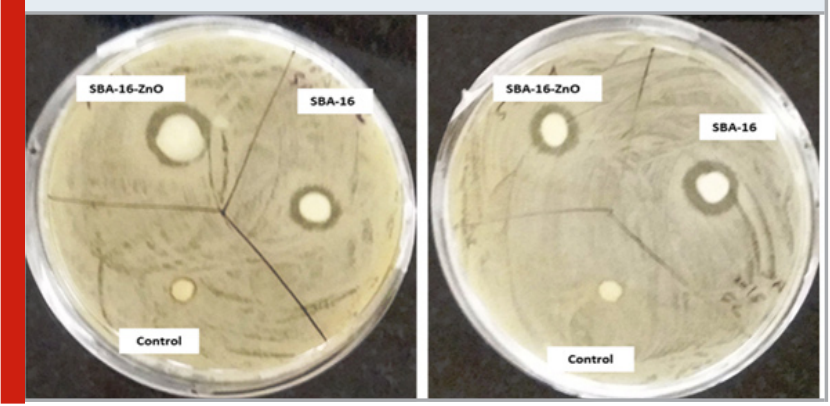

3.6. Anti-Bacterial Activity: Disc diffusion testing of SBA-16-ZnO nanocomposite inhibitions was done. Antibacterial action is shown by both SBA-16 and SBA16-ZnO nanocomposite. The nanoparticles inhibit the development of both bacteria, as seen in Figure 6. In the present, E. coli and S. aureus were shown activity by SBA-16 and SBA-16-Zn0 nanocomposites nanoparticles. The findings demonstrate that the inhibitory zone width is greatest compared with SBA-16 alone for chemically synthesized nanocomposite SBA-16-ZnO (Siddiqi 2018; Johar et al., 2015; Verma et al., 2020; Khanh Nguyen et al., 2020; Narayan et al., 2018).

\section{CONCLUSION}

Zinc Oxide nanoparticles were successfully synthesized and doped into mesoporous SBA-16. $\mathrm{ZnO}$ nanoparticles have been applied to the mesopores of SBA- 16 by the process of post-impregnation. ZnO Nanoparticles have been doped into SBA-16 by studying Fourier Transformed Infrared Spectroscopy XRD and the small X-ray Scattering Graph. The morphological analysis for the sample was performed scanning electron microscopy, and the lattice cell parameter with symmetry was studied with the transmission electron microscope. The result indicated that SBA-16-ZnO nanocomposite exhibit 
significant anti-bacterial properties.

\section{REFERENCE}

A. Kumar, S. Gahlyan, R. Thakur, S. Devi, and S. Duhan (2020). "Synthesis of Mesoporous SBA-16 and SBA16/ZnO Nano-Composite Thin Film for Anti-Biofilm Application," J Nanosci Nanotechnol, vol. 20, no. 7, pp. 4210-4215, doi: 10.1166/jnn.2020.17539.

A. Sirelkhatim et al., (2015). "Review on Zinc Oxide Nanoparticles: Antibacterial Activity and Toxicity Mechanism," Nano-Micro Lett., vol. 7, no. 3, pp. 219-242, doi: 10.1007/s40820-015-0040-x.

D. Cao, S. Gong, X. Shu, D. Zhu, and S. Liang (2019). "Preparation of ZnO Nanoparticles with High Dispersibility Based on Oriented Attachment (OA) Process," Nanoscale Res Lett, vol. 14, no. 1, p. 210, doi: 10.1186/s11671-019-3038-3.

D. Praseptiangga, H. L. Zahara, P. I. Widjanarko, I. M. Joni, and C. Panatarani (2020). "Preparation and FTIR spectroscopic studies of $\mathrm{SiO2-ZnO} \mathrm{nanoparticles}$ suspension for the development of carrageenan-based bio-nanocomposite film," Bikaner, India, p. 100005. doi: 10.1063/5.0003434.

J. González-Rodríguez et al., (2020). Enhanced Photocatalytic Activity of Semiconductor Nanocomposites Doped with Ag Nanoclusters Under UV and Visible Light," Catalysts, vol. 10, no. 1, Art. no. 1, doi: 10.3390/catal10010031.

J. R. Bruckner, J. Bauhof, J. Gebhardt, A.-K. Beurer, Y. Traa, and F. Giesselmann (2021). "Mechanisms and Intermediates in the True Liquid Crystal Templating Synthesis of Mesoporous Silica Materials," J. Phys. Chem. B, vol. 125, no. 12, pp. 3197-3207, doi: 10.1021/ acs.jpcb.0c11005.

K. S. Siddiqi, A. ur Rahman, Tajuddin, and A. Husen (2018). "Properties of Zinc Oxide Nanoparticles and Their Activity Against Microbes," Nanoscale Res Lett, vol. 13, doi: 10.1186/s11671-018-2532-3.

M. A. Johar, R. A. Afzal, A. A. Alazba, and U. Manzoor (2015). "Photocatalysis and Bandgap Engineering Using Zn0 Nanocomposites," Advances in Materials Science and Engineering. https://www.hindawi.com/journals/ amse/2015/934587/ (accessed Feb. 20, 2021).

P. Verma, Y. Kuwahara, K. Mori, R. Raja, and H. Yamashita (2020). "Functionalized mesoporous SBA15 silica: recent trends and catalytic applications," Nanoscale, vol. 12, no. 21, pp. 11333-11363, doi: 10.1039/DONR00732C.

Q. N. Khanh Nguyen, N. T. Yen, N. D. Hau, and H. L. Tran (2020). Synthesis and Characterization of Mesoporous Silica SBA-15 and ZnO/SBA-15 Photocatalytic Materials from the Ash of Brickyards," Journal of Chemistry, vol, p. e8456194, doi: 10.1155/2020/8456194.

R. Narayan, U. Y. Nayak, A. M. Raichur, and S. Garg (2018). Mesoporous Silica Nanoparticles: A Comprehensive Review on Synthesis and Recent Advances," Pharmaceutics, vol. 10, no. 3, doi: 10.3390/ pharmaceutics 10030118.

S. V. Gudkov, D. E. Burmistrov, D. A. Serov, M. B. Rebezov, A. A. Semenova, and A. B. Lisitsyn (2021). "A Mini Review of Antibacterial Properties of $\mathrm{ZnO}$ Nanoparticles," Front. Phys., vol. 0, doi: 10.3389/ fphy.2021.641481.

S.-H. Wu, C.-Y. Mou, and H.-P. Lin,(2013). Synthesis of mesoporous silica nanoparticles," Chem. Soc. Rev., vol. 42, no. 9, pp. 3862-3875, doi: 10.1039/C3CS35405A.

V. Tiwari, N. Mishra, K. Gadani, P. S. Solanki, N. A. Shah, and M. Tiwari, "Mechanism of Anti-bacterial Activity of Zinc Oxide Nanoparticle Against Carbapenem-Resistant Acinetobacter baumannii," Front. Microbiol., vol. 0, 2018, doi: 10.3389/fmicb.2018.01218.

Y. K. Mishra and R. Adelung, "ZnO tetrapod materials for functional applications," Materials Today, vol. 21, no. 6, pp. 631-651, Jul. 2018, doi: 10.1016/j. mattod.2017.11.003.

Y. Wang et al., "Surfactant-assisted Nanocasting Route for Synthesis of Highly Ordered Mesoporous Graphitic Carbon and Its Application in CO 2 Adsorption," Scientific Reports, vol. 6, no. 1, Art. no. 1, May 2016, doi: $10.1038 /$ srep26673.

Y. Zhang, M. K. Ram, E. K. Stefanakos, and D. Y. Goswami, "Synthesis, Characterization, and Applications of ZnO Nanowires," Journal of Nanomaterials, Jul. 17, 2012. https://www.hindawi.com/journals/jnm/2012/624520/ (accessed Feb. 20, 2021). 